\title{
Información o desinformación. Un supuesto complot anarquista contra Negrín
}

\author{
Marina Casanova
}

El movimiento revolucionario que se inició en España en julio de 1936 fue contrarrestado por la decisión de Largo Caballero, en el mes de septiembre, de aunar todas las fuerzas en favor de la unidad estatal. En Cataluña, los anarquistas se incorporaron al Gobierno de la Generalitat y esto produjo divergencias entre las fuerzas libertarias y el modelo revolucionario a seguir.

La progresiva influencia del Partido Comunista en la acción gubernamental, la presencia y ayuda militar de la Unión Soviética, y el aumento de influencia de la UGT y del PSUC en Cataluña desencadenaron los sucesos de mayo de 1937 en Barcelona. El incidente que desencadenó la crisis fue el intento de la Policía de la Generalitat de desalojar a los anarquistas del control que ejercian sobre la Telefónica, aunque en realidad lo que se estaba dirimiendo era la hegemonía entre anarquistas y comunistas.

Los enfrentamientos concluyeron el 7 de mayo, con un balance de 500 muertos y la casi total desaparición de las fuerzas anarquistas de la esfera política, que el 23 de mayo adoptaron en Valencia una serie de acuerdos de no participación con el Gobierno de Negrín, y recomendaron a sus afiliados que tuvieran dispuestas y en buen lugar "todas las posibilidades bélicas de la organización” '. Las armas y municiones que siguieron enviando los anarquistas europeos a los españoles no llegaron a los combatientes del frente, sino que fueron guardadas en lugares seguros para un futuro enfrentamiento.

La prensa francesa, tanto de derechas como de izquierdas, había acogido favorablemente la derrota de los anarquistas en Cataluña y tomó par-

' Peirats, José: Los anarquistas en la crisis política española. Madrid. Ed. Júcar. 1976, pag. 237. 
tido por la República. En opinión de David W. Pike, todas las fuerzas politicas aceptaron la versión oficial de los sucesos de mayo y consideraron a los anarquistas como elementos fuera de las organizaciones regulares ${ }^{2}$.

El 6 de septiembre de 1937 la Política francesa, que no ignoraba estos hechos y que continuaba vigilando a los dirigentes anarquistas refugiados en territorio francés ${ }^{3}$. informó al Ministerio del Interior sobre la organización de un levantamiento de carácter revolucionario que tendría lugar en Cataluña contra el Gobierno de Juan Negrín, basándose en la abundante documentación que había sido interceptada al Centro anarquista de Zurich ${ }^{4}$. Según esta documentación, el Bureau Central de las Organizaciones anarquistas habia sugerido a los anarquistas franceses, tras los sucesos de Barcelona, que proporcionasen dinero y armas para realizar un nuevo movimiento revolucionario. El Prefecto de la Haute Garonne fue informado de la existencia de una organización anarquista en el sudoeste francés dedicada al tráfico y al contrabando de armas que habian sido depositadas en diferentes lugares de los Departamentos de la Haute Garonne, de l'Ariège y de los Pirineos orientales.

Las directrices emanadas de la Central de Zurich señalan como Jefe de la Organización a Wilhem Fusch. Este recordaba a los responsables de las células anarquistas que mantuvieran un estricto secreto para que no se llegara a producir ninguna filtración que hiciese fracasar el levantamiento, expresando además su inquietud ante las investigaciones llevadas a cabo por la Policía francesa, que había detectado el tráfico de armas a causa de ciertas imprudencias. Por ello, les recomendaba que todos los contactos se hiciesen de forma verbal, y en caso de que no fuera posible, destruyeran las comunicaciones escritas lo antes posible. Cada uno de los responsables fue designado con unas siglas y disponía de una serie de créditos en diferentes Bancos de París y de Zurich. Se había previsto el 28 de agosto la llegada de 125 hombres con pasaportes en regla que se dirigirian a Peralta después de haber pasado la frontera por La Junquera.

A finales de agosto, el Centro de Zurich envió instrucciones a los Centros de Perpignan, Carcassonne, Foix y Tarbes sobre la forma de iniciar el levantamiento. En una primera fase se daría la alerta general que pondría en marcha todos los dispositivos preparados para que el alza-

2 PIKE, David W.: Les français et la guerre d'Espagne. Paris. Presses Universitaires de France. Publications de la Sorbonne. 1975, pag. 259.

3 Archives de la Préfecture de Police de Paris. BA-1664. AS. Affaires d'Espagne.

¿ Archivo del Ministerio de Asuntos Exteriores. RE-53. Cpta. 82-83. 
miento se produjese a las veinticuatro horas de haberla recibido. Las disposiciones incluían la concentración de todo el material, municiones y vehículos de enlace, debiendo acudir todos los grupos establecidos en la frontera a los Centros designados, pero de forma individual para no levantar las sospechas de los servicios de vigilancia, y ponerse en contacto con los camaradas españoles.

En una segunda fase se produciría el paso de los hombres y del material a España evitando la violencia, si ello fuese posible, contra los agentes de vigilancia de la Policía francesa. En caso de dificultades, el Centro aconsejaba la rendición y la entrega del material si el hecho tuviese lugar en territorio francés, y la resistencia hasta el último hombre si ya hubiesen franqueado la frontera española.

El 8 de septiembre, el Inspector Principal de la Policia Especial encargado del servicio de Vigilancia de Toulouse dio a conocer el resultado de las investigaciones relacionadas con el levantamiento que, en su opinión, consistía en una copia más elaborada de los sucesos de mayo en Barcelona.

Las autoridades francesas consideraron que el posible levantamiento anarquista no sólo podría tener repercusiones en España, sino muy especialmente en Francia, en cuyo territorio fronterizo se habian instalado pequeñas células revolucionarias, que hasta agosto de 1937 sólo habian mantenido reuniones esporádicas para captar nuevos afiliados, pero nunca habian llevado a cabo grandes mítines ni acciones espectaculares.

Aunque el contenido de la documentación interceptada al Centro de Zurich sorprendió a las autoridades francesas tanto por el número de hombres y de armas dispuestos para el alzamiento, como por la precisión de las fechas en que tendría lugar, el Inspector Principal puso en duda la veracidad del proyecto argumentando que sólo se trataba de armamento que los anarquistas españoles habian ido poco a poco almacenando en diferentes puntos de la frontera franco-española. No obstante, la Policía francesa consideró prudente mantener una discreta vigilancia para evitar que se pudiera llevar a cabo cualquier tipo de acción revolucionaria ${ }^{5}$. Asimismo transmitió copias de las cartas interceptadas a los Servicios de Información Diplomáticos republicanos de Sète y de Toulouse que, a partir de ese momento, llevaron a cabo numerosas investigaciones sobre las actividades de los dirigentes anarquistas en Francia.

\footnotetext{
5 AMAE. RE-53. Cpta. 83-84.
} 
Las informaciones enviadas al Ministerio de Estado español por los Servicios de Información Diplomáticos de Sète indicaban la preparación de una insurrección en Barcelona, que sería realizada por los anarquistas a finales de septiembre coincidiendo con un ataque masivo de las fuerzas rebeldes sobre Madrid. Los anarquistas habrían establecido una vasta red de almacenamiento de armas entre Sète y Cerbère que serían trasladadas a La Junquera en la fecha convenida por la insurrección. Pero además afirmaban que la Central anarquista de Zurich actuaría de acuerdo con las fuerzas de los rebeldes quienes serían junto a Alemania los verdaderos organizadores del complot ${ }^{6}$.

Por su parte, los Servicios de Información Diplomáticos de Toulouse interpretaron que el proyectado alzamiento estuvo patrocinado por Alemania e Italia, quienes pretendían provocar un levantamiento, aparentemente anarquista, pero dirigido y controlado por sus redes de espionaje. Según sus informes, el Centro principal se encontraba en París y contaba con ramificaciones en diferentes ciudades francesas. La Dirección estaba formada por Liberato Minué, Eugenio Fuentes, Manuel Mascarell, José Elizalde y Roca Gálvez. En ningún momento actuaron como agentes provocadores, sino como parte del conjunto de fuerzas antifascistas españolas y recibian por ello el apoyo de los centros oficiales tanto franceses como españoles. Los anarquistas editaban en París un semanario, «Nueva España Antifascista", aunque los Servicios de Información de Marsella no lo consideraron como portavoz de todo el movimiento, sino de un grupo de personas de nacionalidad española pertenecientes, unos a la Federación Anarquista Francesa y otros a la Unión Anarquista, que se arrogaron la representatividad de la FAl y de la CNT ${ }^{7}$.

Por otro lado, los Servicios de Información Diplomáticos de Toulouse orientaron sus investigaciones para descubrir los posibles contactos que se hubieran realizado entre los anarquistas y los rebeldes. El 27 de enero de 1937, el antiguo Secretario de la Legación española en Caracas y miembro de "La Grande Frégate" ", Mariano Iturralde llegó a Toulouse con el fin de entrevistarse con el agente de enlace entre los rebeldes y la FAl. La reunión se fijó para el 19 de febrero de 1937 coincidiendo con un baile organizado por la Duquesa de Guisa para recaudar fondos para la causa franquista.

AMAE. RE.53. Cpta. 79.

7 AMAE. RE-50. Cpta. 58.

" "La Grande Frègate" era uno de los centros de los Servicios de Información de la Frontera del Norte de España (SIFNE), creados por los rebeldes en el sur de Francia. 
La representación de los agentes franquistas estuvo formada por José Antonio Azcárate, Mariano Iturralde, Alfonso Muñoz y un Comandante del ejército rebelde. Por parte de la FAl acudieron José Elizalde, Nicolás Urrieta y Alba Resurrección. Las dos representaciones trataron de allanar el terreno para lograr un futuro entendimiento, pero los requerimientos formulados por los anarquistas, tales como la libertad para sus miembros detenidos, el mantenimiento de los sindicatos o la entrega de una importante cantidad de dinero para ayudar a sus compañeros en dificultades, parecieron improcedentes a la representación franquista. Ante la imposibilidad de llegar a un acuerdo, ambas delegaciones optaron por dar cuenta de sus conversaciones a sus dirigentes respectivos y fijar una nueva entrevista.

El Embajador de España en París, Angel Ossorio y Gallardo, había enviado a un confidente de la Embajada al baile benéfico para que le informara de lo sucedido ${ }^{9}$. El Embajador conocía las actividades de uno de los miembros de la delegación anarquista, Alba Resurrección, a quien hasta entonces se habia negado recibir en la Embajada, aunque se vio obligado a hacerlo cuando fue designado para llevar a Valencia las conclusiones de la entrevista. También sabía dónde se encontraban los depósitos de armas que los anarquistas habian escondido en París, pero no lo reveló a las autoridades francesas debido a la falta de coordinación entre los diferentes Servicios de Información de la República existentes en Francia, que actuaban siguiendo consignas diferentes a las de la Legación, aunque utilizando su cobertura. No obstante, comunicó al Ministerio de Estado la preparación de un alzamiento anarquista en Barcelona, posibilidad que el propio Presidente de la República puso en duda ${ }^{10}$.

El Gobierno republicano tampoco consideró oportuno revelar a la Policía francesa dónde se encontraban los depósitos de armas por temor a la intervención de determinadas personas de la Sûreté, que según las informaciones de los Servicios de Información, estaría más o menos comprometidas con los rebeldes ".

La documentación interceptada al Centro de Zurich ha dado lugar a diferentes interpretaciones. Tanto la Policia francesa como las autoridades

9 AMAE. RE-53. Cpta. 82-83. Ossorio a Ministro de Estado.

Parece ser que el confidente traicionaba tanto a los fascistas como a los anarquistas, y según Ossorio, no sería de extrañar que tambien les traicionase a ellos.

in Azana, Manuel: Memorias politicas y de guerra. Tomo II. Barcelona. Crítica. Grijalbo. 1981, pág. 258.

" AMAE. RE-96. Cpta. 6. 
republicanas conocieron en todo momento los preparativos del supuesto golpe revolucionario, aunque no le dieron mayor credibilidad. Algunas opiniones recogidas por la Policía francesa en Toulouse señalaban que los anarquistas trabajaban conjuntamente con Franco. El Inspector francés encargado del caso no rechazaba esta posibilidad, porque consideraba que el General rebelde sería el único beneficiario, y que no tendría ninguna razón para oponerse a un levantamiento que debilitaría las fuerzas de sus enemigos.

Efectivamente ya se habían producido contactos entre los anarquistas y las autoridades rebeldes. El 18 de septiembre de 1937 un grupo de hombres armados intentó apoderarse del submarino republicano $\mathrm{C}-2$ que se encontraba en el puerto de Brest para efectuar reparaciones, pero el resultado de la operación fue un fracaso siendo inculpado el Jefe de la Comandancia de Irún, el Comandante Julián Troncoso ${ }^{12}$. Según un informe de los Servicios de Información Diplomática de Toulouse, unos días antes del intento de captura del C-2, se celebró una entrevista entre el Comandante Troncoso, el Jefe de los Servicios de Información franquistas en el sur de Francia, José Bertrán y Musitu y una representación de los anarquistas encabezada por Viriato Minué. La entrevista tuvo lugar en la habitación que ocupaba Bertrán y Musitu en el Hotel Quai d'Orsay, y durante ella los representantes de Franco propusieron a la delegación anarquista que organizase un movimiento similar al de los sucesos de mayo en Barcelona. A cambio de ello recibirían diez millones de francos, garantías de seguridad, pasaportes para todas las personas que se indicaran, y todo el material necesario para la realización del levantamiento, pidiéndoles solamente un plano de la situación exacta del frente de Aragón. Siempre según los Servicios de Información de Toulouse, Minué pidió tiempo para poner en conocimiento de la Regional de Barcelona la propuesta, y una vez analizada concertar una nueva entrevista ${ }^{13}$.

Una de las posibles interpretaciones apuntada por la Policía francesa fue que la documentación habria sido redactada por los comunistas para comprometer al Presidente de la Generalitat, Lluis Companys, y una vez realizado el alzamiento, culpar por un lado a los anarquistas, y por otro acusar a Companys de haber tenido trato con las fuerzas franquistas para obtener un mayor control sobre la autonomía catalana.

\footnotetext{
12 AMAE. RE-44. 12-9-1937.

R-1275. Exp. 216. 8-10-1937.

13 AMAE. RE-53. Cpta. 83-84.
} 
Efectivamente, en el último párrafo de uno de los documentos supuestamente enviados por el Centro Anarquista de Zurich puede leerse: "Nuestro Nachrichten Buro nos ha hecho saber, y nos ha sido confirmado por Londres, que habrian entrado en tratos emisarios de Companys y agentes más o menos autorizados de nuestros enemigos para obtener una rendición sin condiciones de aquéllos que durante meses han oprimido, perseguido y martirizado a nuestros camaradas catalanes. Después de Bilbao y de Santander, los cobardes de Barcelona escaparian a su destino. Haz saber a todos que sus planes han fracasado y que si la acción es corta será suficiente para asegurar la suerte que merecen aquellos que han sido los verdugos de nuestros padres. Más vale tratar con el león que con el chacal».

El que fuera Ministro de Justicia de la Repúbica, Manuel de Irujo, declaró en 1974 que la documentación procedente del supuesto Centro Anarquista de Zurich que había interceptado la Policía francesa, seguía el mismo patrón que los falsos documentos presentados contra el POUM en octubre de 1938, y negó categóricamente que Companys hubiera tenido contacto alguno con agentes de Franco ${ }^{14}$.

La posibilidad de que fueran los comunistas los autores de los documentos interceptados también es apuntada por David Pike que afirma que se trataria de un montaje realizado por Stalin para contrarrestar las posibles represalias del POUM después de mayo de 1937, y además señala que solamente en dos documentos figura una dirección en Viena, la del Auskunftsburo, en el 21 de la Zeltgasse, cuando entre 1937 y 1938 nunca existió ni el citado centro ni el número 21. Por lo que se refiere a los supuestos documentos emitidos por la Central de Zurich, en ninguno de ellos figura la dirección del remitente.

Es posible que después de la derrota de mayo de 1937, algunos grupos anarquistas aspiraran a tomarse la revancha y que llegaran a establecer contactos con los agentes franquistas, pero es difícil de aceptar que tales proyectos de colaboración para realizar un alzamiento llegasen a prosperar. En primer lugar por la marginación en la que habian quedado las fuerzas anarquistas después de los sucesos de Barcelona, y en segundo lugar porque una alianza entre las fuerzas del POUM, los nazis y los rebeldes de Franco carece de todo sentido.

En cualquier caso, con las informaciones que disponen actualmente los historiadores no es posible dar por cerrado este caso, y ninguna de las

\footnotetext{
14 Vid. PIKE, op. cit., pág. 411.
} 
interpretaciones apuntadas puede ser deshechada a priori aunque tengan una mayor o menor base de verosimilitud. El acceso a los Archivos de la antigua Unión Soviética y de los países del Este y la consulta de sus respectivos fondos permitirá abrir nuevos cauces a la investigación, aunque una gran parte de los archivos rusos, por ejemplo los archivos militares, no son todavía accesibles. Terminaré con una historia contada por el Profesor checo Karel Bartosek: Reunidas las almas de los grandes jefes militares de todos los tiempos, declaran de común acuerdo que hubieran dominado el mundo si hubieran tenido la técnica militar actual. Al no participar Napoleón distraído en la conversación, los demás, intrigados, le preguntan su opinión. "Queridos amigos, si yo hubiera tenido el Servicio de Información de la Unión Soviética, todavia hoy se ignoraría que fui derrotado en Waterloo" ${ }^{15}$.

15 BARTOSEK, Karel: "Prague 1968, la fin des illusions", en Historia, Special. Paris. Noviembrediciembre 1996. № 44, pág. 120. 